Published in final edited form as:

Curr Opin Nephrol Hypertens. 2014 January ; 23(1): 25-31. doi:10.1097/01.mnh.0000437332.31418.e0.

\title{
Kidney Injury, Stem Cells and Regeneration
}

\author{
Benjamin D. Humphreys $\mathbf{s}^{1,2,3}$ \\ ${ }^{1}$ Renal Division, Brigham and Women's Hospital, Boston, MA, USA \\ ${ }^{2}$ Harvard Medical School, Boston, Massachusetts, USA \\ ${ }^{3}$ Harvard Stem Cell Institute, Cambridge, Massachusetts, USA
}

\begin{abstract}
Purpose-This review summarizes the most recent advances in stem cell and regenerative approaches to treat kidney injury, and highlights areas of active controversy. Over the last year a number of findings have been reported that have brought this field much closer to clinical translation.

Recent Findings-Recent progress in regenerative nephrology includes the directed differentiation of embryonic stem cells to kidney fates, understanding the proliferative capacity of tubules after injury, the use of mesenchymal stem cells for kidney disease and tissue engineering approaches to renal replacement. Controversies persist, however, including whether adult epithelial stem cells exist at all, the best therapeutic strategy for the treatment of kidney injury and how to use mesenchymal stem cells optimally for the prevention of acute kidney injury.
\end{abstract}

Summary-While recent progress in kidney regeneration is very encouraging, current controversies must be resolved before clinical breakthroughs can occur.

\section{Keywords}

Kidney stem cell; mesenchymal stem cell; directed differentiation; reprogramming; regeneration

\section{INTRODUCTION}

Stem cell and regenerative medicine approaches to kidney injury are among the most exciting concepts to have emerged in nephrology over the last decade. While progress has been slow until recently, the field now appears poised to advance rapidly. I will review the discoveries driving this innovation, but first summarize some fundamental principles of kidney regenerative biology already established and widely agreed upon. These include the discovery that multipotent renal stem cells exist in the developing mammalian kidney; that adult nephron has a robust but not inexhaustible capacity to repair after acute injury; and the revelation that lower vertebrates such as zebrafish are capable of generating entirely new nephrons from an adult kidney stem cell population.

During nephrogenesis, the kidney develops from intermediate mesoderm through a process of reciprocal inductive signals exchanged between the ureteric bud and the cap mesenchyme. Cells from cap mesenchyme, itself derived from intermediate mesoderm, condenses to form the pre-tubular aggregate and subsequently undergoes mesenchymal-to-

Correspondence: Dr. Benjamin D. Humphreys, Harvard Institutes of Medicine, Room 554, 4 Blackfan Circle, Boston, MA 02115. Phone: 617-525-5971; Fax: 617-525-5965; bhumphreys@ partners.org.

Disclosure

The author declares no competing interests. 
epithelial transition to form the renal vesicle. This further develops into an increasingly complicated structure ultimately forming the entire nephron ${ }^{1}$. Elegant studies have shown conclusively that the cap mesenchyme contains multipotent kidney progenitors that both self-renew and differentiate, forming all the epithelial cells found along the nephron except for collecting duct ${ }^{2-4}$. These findings have provided important markers, such as Six 2 or OSR1, to aim for when inducing embryonic stem cells toward kidney progenitor fates, as discussed below.

Another established concept is that proximal tubule epithelia undergo proliferative expansion after acute injury to repair acute damage ${ }^{5,6}$. Epithelial cell proliferation helps restore cells lost to apoptosis or necrosis during the insult ${ }^{7}$. While the burst of proliferation in proximal tubule after injury is widely accepted, understanding the signals that drive epithelial proliferation is now a major focus of AKI research. Importantly, the cellular source of these dividing cells remains unresolved.

Finally, although mammals cannot grow new nephrons after kidney development ceases, one of the most exciting recent findings has been the indisputable demonstration that lower vertebrates are able to regenerate entire nephrons after injury. Elger and colleagues first provided strong histologic evidence that the elasmobranch skate kidney could generate new nephrons after partial nephrectomy ${ }^{8}$. But the elegant work of Davidson provided indisputable evidence that adult kidney stem cells exist in zebrafish, and can be serially transplanted ${ }^{9}$. Collectively these studies raise an important question: Why have lower vertebrates retained a capacity for post-natal nephron neogenesis that mammals have lost? A better understanding of this issue will provide critical insight into kidney regeneration.

In the following sections I outline four areas of ongoing controversy in the field of regenerative nephrology. While not comprehensive, for example I will not cover glomerular regeneration ${ }^{10,11}$, this list includes controversies that are especially relevant to acute kidney injury.

\section{DO TUBULAR STEM CELLS EXIST?}

A basic prerequisite for the design of a stem cell or regenerative approach to kidney injury is a clear understanding of how the adult kidney repairs itself normally. Yet this remains a contentious and controversial area. Two competing theories have arisen to explain the origin of proliferating tubular epithelia after acute injury: (1) A stem or progenitor cell generates new epithelia, or (2) fully differentiated epithelia dedifferentiate, re-enter the cell cycle and generate new epithelial cells through self-duplication. Support for both theories exists.

Arguing for the epithelial stem cell theory, a variety of candidate progenitors cells have been described. Genetic fate mapping of $\mathrm{nFatC} 1+$ cells in AKI suggest that these may represent an intratubular progenitor population ${ }^{12}$. Importantly, individual proximal tubule cells in humans that express vimentin, CD24 and CD133 have been recently identified, and these putative progenitor cells are present both in parietal epithelium and also scattered throughout the proximal tubule. When isolated ex vivo, these cells can form spheres and clonally expand, and they ameliorate AKI and apparently contribute to epithelial lineage in experimental models ${ }^{13-16}$. Recently LGR5 was shown by lineage analysis to mark a distal tubule progenitor population during development, providing further support to the notion that epithelial progenitors could exist in adult kidney ${ }^{17}$. Other characteristics including side population, label retention and clonality have been reported to enrich for putative intratubular epithelial stem cells ${ }^{18-21}$.

On the other hand, we have shown using a genetic lineage analysis strategy that no extratubular stem or progenitor population migrates into the tubule during repair from 
AKI ${ }^{22}$. Moreover, the traditional model for AKI repair holds that epithelial repair after injury occurs by dedifferentiation and proliferation of surviving epithelial cells 6,23 . Support from this model derives from the finding that differentiated proximal tubule cells are poised in G1, ready to re-enter the cycle after injury ${ }^{24}$. Because our genetic approach could not distinguish a dedifferentiation model from a stem cell model of epithelial repair, we have also tracked the proliferative history of proximal tubule epithelia after acute injury using sequential pulses of thymidine analog. This study showed that cell division at different timepoints during repair is by separate, random, fractions of the total epithelium. These results argue strongly that repair is not through a minority population of stem cells that proliferate rapidly, but rather all surviving epithelial cells have an equivalent capacity for repair ${ }^{25}$. On the other hand, this result has actually been interpreted by others to support a stem cell based repair mechanism, reasoning that tubular progenitors preferentially survive and therefore represent the dominant population among surviving cells and thus divide only once or twice during repair 26,27 .

Thus it remains unclear whether an intratubular progenitor may exist or not. Importantly, Smeets et al. has recently showed that Kidney injury molecule-1 (KIM-1) is coexpressed with human vimentin+CD24+CD133+ tubule cells. Vimentin and Kim-1 are tubular injury markers ${ }^{28,29}$ and these authors observed no basal expression of either marker in healthy rat kidney but upregulation of both proteins after injury. Therefore they argue that vimentin +CD24+CD133+ cells do not reflect a preexisting progenitor population but rather reflect transient dedifferentiation ${ }^{30}$. This is a provocative concept because it may explain the consistent observations of CD24+CD133+ cells in human, suggesting that these may reflect individual cells undergoing dedifferentiation, perhaps due to local stresses or homeostatic repair. Resolution of this debate, however, will require definitive evidence from genetic lineage analysis in vivo. The two possible mechanisms of epithelial repair are summarized in Figure 1. Those studies are currently underway in several laboratories, so expect more developments in this rapidly moving field.

\section{WHAT IS THE ROLE OF MSC-BASED THERAPIES FOR TREATMENT OF AKI?}

As a regenerative approach already in translation, with mesenchymal stem cell (MSC) based clinical trials for treatment of kidney disease underway, MSC have attracted intense attention for their potential therapeutic use ${ }^{31}$. MSCs act in a paracrine fashion to exert antiinflammatory, pro-repair, immunomodulatory effects ${ }^{32}$. These are accomplished through secretion of soluble factors including growth factors and angiogenic cytokines. MSCs also secrete exosomes containing microRNAs that mediate part ofthe beneficial effects of these cells after injection ${ }^{33,34}$. A series of careful studies have proven that MSCs do not integrate into kidney parenchyma, and in fact reside in kidney only transiently after injection ${ }^{35}$. Nevertheless, MSCs have been shown to ameliorate a wide variety of kidney diseases, from AKI to CKD to glomerular disease ${ }^{36}$.

Unique among stem cell approaches to kidney disease, a Phase I clinical trial has recently been completed testing the safety of MSCs in patients undergoing on-pump cardiac surgery at high risk for developing AKI. This study enrolled 16 patients, and administered escalating doses of MSCs into the distal thoracic aorta. Study participants were followed up for six months, and no specific adverse events were reported. A secondary objective of the trial was to compare patients that received MSC with matched historical controls that had not received stem cell therapy. This analysis suggests that MSCs afford early and late kidney protection, as well as decreased hospital length of stay ${ }^{37}$. These results have allowed a privately held company, allocure, to initiate a Phase II trial designed as a randomized, 
double-blind, placebo-controlled multicenter trial to assess the efficacy of MSCs in approximately 200 cardiac surgery patients (NCT01602328, www.allocure.com).

Despite the compelling progress that these two clinical trials demonstrate, unanswered questions remain concerning the how best to apply MSCs to kidney disease. A central problem is the therapeutic mechanism, which remains poorly defined. MSCs do not engraft in kidney when injected intra-arterially, and when injected intravenously, they embolize in lung ${ }^{38}$. Therefore these studies are not cell transplantation, but rather infusion of cells that exert effects through paracrine mechanisms - so this is not a stem cell replacement therapy, because the cells do not engraft. This implies that if we can identify the bioactive substances secreted by MSCs, that infusion of these alone, without cells, would be just as good or better. Whether MSC release bioactive molecules in a temporal sequence - in effect responding to a changing environment - is not known. In preclinical studies, however, conditioned media from MSCs protected kidneys from acute injury just as well as injection of the cells did ${ }^{39}$. Clearly an incomplete understanding of the mechanism of action of this therapy is no reason not to pursue these clinical trials but more basic research into MSC biology and kidney protection is required.

\section{HOW CAN EMBRYONIC STEM CELLS AND INDUCED PLURIPOTENT CELLS BE USED TO TREAT KIDNEY INJURY?}

The ability to direct the differentiation of embryonic stem cells to any cell type of interest has always been recognized as a powerful and inexhaustible source for cell replacement therapies. Yamanaka's Nobel prize-winning discovery that mature somatic cells can be reprogrammed to become pluripotent stem cells (induced pluripotent stem cells, iPSCs) by expression of four transcription factors has shifted paradigms and accelerated the clinical development of cell therapies 40,41 . Because iPSCs can be generated easily from any patient, they offer the promise of disease modeling, toxicity testing and personalized cell therapies without fear of immunologic rejection.

Progress towards generating kidney cell types from embryonic stem cells (ES cells) or iPSCs has been notably slow compared to other fields, until recently. Full protocols for the derivation of hepatocytes, neurons and cardiac myocytes were established years ago ${ }^{42-44}$, and these have catalyzed important new discoveries such as the possibility of completing a clinical trial in a petri dish ${ }^{45,46}$. No efficient protocol has existed in kidney, but recent progress gives encouragement that this field is about to break open.

Several groups have demonstrated that exposure of ES or iPS cells to factors required for renal specification, such as retinoic acid, activin A and bone moorphogenic proteins does induce differentiation into renal lineage cells including intermediate mesoderm, as well as individual apparently differentiated cells, such as proximal tubule or podocyte ${ }^{47-51}$. However, a limitation to these efforts has been the relatively inefficient differentiation process, which can take weeks, as well as the low yield of differentiated cells. The field has also been held back by the absence of a robust assay to test the functional capacity of these cells, in addition to their expression of typical markers. Recently the Little group has described a novel reaggregation assay, in which embryonic mouse kidney is disaggregated, then re-aggregated along with exogenous cell populations, and subsequently cultured ${ }^{52}$. This in vitro system provides a powerful platform on which to assess the differentiation and incorporation potential of cells derived from ES or iPSC cultures, and should stimulate further development of directed differentiation protocols.

Mae has reported a protocol for the most efficient differentiation of intermediate mesoderm, from human ES cells, to date. Taking advantage of the fact that OSR1 expression defines 
intermediate mesoderm, these authors knocked in a green fluorescent protein (GFP) reporter into the OSR1 locus. This allowed them to assay different differentiation protocols, using gain of GFP fluorescence as a readout for intermediate mesoderm fates. Their protocol, which involves sequential activin A and BMP7 treatment with continuous canonical Wnt pathway activation, resulted in 90\% purity for OSR1-GFP cells after about 15-20 days ${ }^{53}$. Notably, they also showed incorporation of these cells into differentiated tubular structures during re-aggregation organ culture, albeit at a relatively low frequency of 5\%. This is an important finding, one that is sure to stimulate further refinements in the directed differentiation of ES and iPS cells to kidney fates.

Besides generating more efficient and robust differentiation protocols, an additional challenge in this field is to understand the stability of the differentiation state achieved. This will require a deeper understanding of the mechanisms driving and maintaining renal cell fates which remain obscure. Rather than induce the differentiation of kidney cell types from multipotent progenitors, an important new question in the field is whether direct reprogramming, from one differentiated cell type to another, ca achieve the same goals as directed differentiation. This concept was first shown by Zhou et al. in reprogramming pancreatic exocrine cells to pancreatic beta-cells ${ }^{54}$. Very recently, the first instance of kidney reprogramming was reported by Little's group. This elegant paper screened various combinations of transcription factors and identified the combination of SIX1, SIX2, OSR1, EYA1, HOXA11, and SNAI2 that were able to reprogram epithelial cells into Six2+ nephron progenitors ${ }^{55}$. These cells were fully able to differentiate into epithelial cells in a re-aggregation assay. Whether created through differentiation or reprogramming, new strategies for achieving integration of these cells within the kidney parenchyma will be required. Certainly one promising use is in tissue engineering, as discussed below.

\section{ARE TISSUE ENGINEERING APPROACHES VIABLE AS A RENAL REPLACEMENT STRATEGY?}

At the beginning of the stem cell era, there was enthusiasm for the concept of growing a new kidney, either in a dish, or through transplantation of embryonic tissue into a host (reviewed in ${ }^{56}$ ). But the challenges to growing a functional kidney soon became evident, dampening enthusiasm. Unlike single cell disorders like diabetes or amyotrophic lateral sclerosis, the challenge with kidney failure is the creation of a functional organ comprised of about 30 cell types organized in a precise 3-dimensional structure. Even after this, how can the host blood supply integrate into the graft? How to plumb in the collecting system to existing ureters? Over the last two years, however, substantial progress in tissue engineering approaches has been made that suggest that many of these problems are at least tractable, though far from being solved.

Historically, two different strategies have been employed to engineer a kidney: combining synthetic components with cells in a hybrid device, and generating a transplantable kidney entirely from cells. While hybrid devices continue to develop, they will be only briefly summarized here. Humes and colleagues successfully designed renal assist device (RAD), consisting of a conventional hemofilter in series with a bioreactor containing thousands of hollow microfibers lined by kidney epithelial cells. After filtration in the conventional hemofilter, the ultrafiltrate passes through the lumen of the bioreactor while the blood is pumped through the extracapillary space. Although not in direct contact with the cells, the blood is modified by the cells, including reduction in pro-inflammatory cytokines and other mediators (reviewed in ${ }^{57}$ ). The RAD made it into clinical trials, as far as a Phase 2a safety and preliminary efficacy trial, but ran into manufacturing and the Phase $2 b$ trial was not completed ${ }^{58,59}$. Despite the suspended clinical trial of the RAD, these devices continue to 
be developed, including portable or even implantable ones, and this field remains promising for treatment of ESRD.

A strategy combing renal progenitor cells with a biocompatible scaffold, rather than an engineered synthetic one has recently been reported and represents a remarkable technical feat. Song and colleagues decellurized an isolated rat kidney with a detergent solution to reveal the extracellular matrix, including vasculature, glomerular basement membrane and tubular basement membranes ${ }^{60}$. They subsequently devised methods to seed the vasculature with cultured endothelial cells, and the tubules and glomeruli with rat kidney progenitor cells isolated from embryonic rat kidney. These single cells contained progenitors for all tubule components as well as interstitium. After reseeding of the kidney scaffold, cells differentiated and expressed appropriate cell-cell contacts and markers of differentiated cells. When delivered perfusate, these regenerated kidneys produced urine and filtrate that suggested active absorptive and secretory function. Most remarkably, when transplanted orthotopically in rat, with renal artery and vein anastomosed to the regenerated kidney, it also produced a filtrate with less glycosuria and albuminuria than simple decellurized kidneys, strong evidence suggesting the regenerated kidney restored macromolecular sieving and glucose reabsorption. This study focuses attention on the importance of kidney scaffolding in providing cues for progenitors to differentiate apropriately. It will be particularly interesting to combine this decellularization approach with other sources of kidney progenitors, such as directed differentiation or reprogramming. Figure 2 summarizes the ways that stem cell biology and artificial kidneys may be combined to provide a source for transplantable engineered kidneys to patients.

\section{CONCLUSION}

The recent advances in stem cell and regenerative approaches to treating kidney injury show remarkable promise. While it is not clear to what extent some of these approaches are truly "regenerative," since they may actually target endogenous repair programs, there is no question that we are much closer now to new and innovative approaches to treat kidney disease than at any other point in the stem cell era.

\section{Acknowledgments}

I apologize to those authors whose works I could not include due to space constraints. This work was supported by grants from the NIH (DK088923), the Harvard Stem Cell Institute and an Established Investigator Award from the American Heart Association.

\section{References}

1. Little MH, McMahon AP. Mammalian kidney development: principles, progress, and projections. Cold Spring Harbor perspectives in biology. 2012; 4

2. Herzlinger D, Koseki C, Mikawa T, et al. Metanephric mesenchyme contains multipotent stem cells whose fate is restricted after induction. Development. 1992; 114:565-572. [PubMed: 1618128]

3. Kobayashi A, Valerius MT, Mugford JW, et al. Six2 defines and regulates a multipotent selfrenewing nephron progenitor population throughout mammalian kidney development. Cell Stem Cell. 2008; 3:169-181. [PubMed: 18682239]

4. Boyle S, Misfeldt A, Chandler KJ, et al. Fate mapping using Cited1-CreERT2 mice demonstrates that the cap mesenchyme contains selfrenewing progenitor cells and gives rise exclusively to nephronic epithelia. Dev Biol. 2008; 313:234-245. [PubMed: 18061157]

5. Cuppage FE, Neagoy DR, Tate A. Repair of the nephron following temporary occlusion of the renal pedicle. Lab Invest. 1967; 17:660-674. [PubMed: 6074497]

6. Witzgall R, Brown D, Schwarz C, et al. Localization of proliferating cell nuclear antigen, vimentin, c-Fos, and clusterin in the postischemic kidney. Evidence for a heterogenous genetic response 
among nephron segments, and a large pool of mitotically active and dedifferentiated cells. J Clin Invest. 1994; 93:2175-2188. [PubMed: 7910173]

7. Guo JK, Cantley LG. Cellular maintenance and repair of the kidney. Annual review of physiology. 2010; 72:357-376.

8. Elger M, Hentschel H, Litteral J, et al. Nephrogenesis is induced by partial nephrectomy in the elasmobranch Leucoraja erinacea. J Am Soc Nephrol. 2003; 14:1506-1518. [PubMed: 12761251]

9. Diep CQ, Ma D, Deo RC, et al. Identification of adult nephron progenitors capable of kidney regeneration in zebrafish. Nature. 2011; 470:95-100. [PubMed: 21270795]

10. Appel D, Kershaw DB, Smeets B, et al. Recruitment of podocytes from glomerular parietal epithelial cells. J Am Soc Nephrol. 2009; 20:333-343. [PubMed: 19092119]

11. Ronconi E, Sagrinati C, Angelotti ML, et al. Regeneration of glomerular podocytes by human renal progenitors. J Am Soc Nephrol. 2009; 20:322-332. [PubMed: 19092120]

12. Langworthy M, Zhou B, de Caestecker M, et al. NFATc1 identifies a population of proximal tubule cell progenitors. J Am Soc Nephrol. 2009; 20:311-321. [PubMed: 19118153]

13. Lindgren D, Bostrom AK, Nilsson K, et al. Isolation and characterization of progenitor-like cells from human renal proximal tubules. Am J Pathol. 2011; 178:828-837. [PubMed: 21281815]

14. Angelotti ML, Ronconi E, Ballerini L, et al. Characterization of renal progenitors committed toward tubular lineage and their regenerative potential in renal tubular injury. Stem Cells. 2012; 30:1714-1725. [PubMed: 22628275] **This article provides strong evidence that human kidney contains a scattered population of CD24+CD133+ cells that contribute to repair after injury. When injected into SCID mice with AKI these progenitors improved kidney function.

15. Kim K, Park BH, Ihm H, et al. Expression of stem cell marker CD133 in fetal and adult human kidneys and pauci-immune crescentic glomerulonephritis. Histol Histopathol. 2011; 26:223-232. [PubMed: 21154236]

16. Loverre A, Capobianco C, Ditonno P, et al. Increase of proliferating renal progenitor cells in acute tubular necrosis underlying delayed graft function. Transplantation. 2008; 85:1112-1119. [PubMed: 18431230]

17. Barker N, Rookmaaker MB, Kujala P, et al. Lgr5(+ve) stem/progenitor cells contribute to nephron formation during kidney development. Cell reports. 2012; 2:540-552. [PubMed: 22999937] *This study used rigorous lineage tracing to show that during nephrogenesis, Lgr5 expression defines an intrtubular progenitor population that contributes to differentiated cells in the thick ascending limb and connecting segment.

18. Kitamura S, Yamasaki Y, Kinomura M, et al. Establishment and characterization of renal progenitor like cells from S3 segment of nephron in rat adult kidney. Faseb J. 2005; 19:17891797. [PubMed: 16260649]

19. Gupta S, Verfaillie C, Chmielewski D, et al. Isolation and characterization of kidney-derived stem cells. J Am Soc Nephrol. 2006; 17:3028-3040. [PubMed: 16988061]

20. Maeshima A, Sakurai H, Nigam SK. Adult kidney tubular cell population showing phenotypic plasticity, tubulogenic capacity, and integration capability into developing kidney. J Am Soc Nephrol. 2006; 17:188-198. [PubMed: 16338966]

21. Challen GA, Bertoncello I, Deane JA, et al. Kidney Side Population Reveals Multilineage Potential and Renal Functional Capacity but also Cellular Heterogeneity. J Am Soc Nephrol. 2006; 17:1896-1912. [PubMed: 16707564]

22. Humphreys BD, Valerius MT, Kobayashi A, et al. Intrinsic epithelial cells repair the kidney after injury. Cell Stem Cell. 2008; 2:284-291. [PubMed: 18371453]

23. Vogetseder A, Palan T, Bacic D, et al. Proximal tubular epithelial cells are generated by division of differentiated cells in the healthy kidney. Am J Physiol Cell Physiol. 2007; 292:C807-C813. [PubMed: 16987990]

24. Vogetseder A, Picard N, Gaspert A, et al. Proliferation capacity of the renal proximal tubule involves the bulk of differentiated epithelial cells. Am J Physiol Cell Physiol. 2008; 294:C22-C28. [PubMed: 17913845]

25. Humphreys BD, Czerniak S, Dirocco DP, et al. Repair of injured proximal tubule does not involve specialized progenitors. Proc Natl Acad Sci U S A. 2011; 108:9226-9231. [PubMed: 21576461] 
26. Romagnani P, Lasagni L, Remuzzi G. Renal progenitors: an evolutionary conserved strategy for kidney regeneration. Nature reviews Nephrology. 2013; 9:137-146.

27. Romagnani P. Of mice and men: the riddle of tubular regeneration. J Pathol. 2013; 229:641-644. [PubMed: 23299489]

28. Wallin A, Zhang G, Jones TW, et al. Mechanism of the nephrogenic repair response. Studies on proliferation and vimentin expression after 35S-1,2-dichlorovinyl-L-cysteine nephrotoxicity in vivo and in cultured proximal tubule epithelial cells. Lab Invest. 1992; 66:474-484. [PubMed: 1374823]

29. Ichimura T, Bonventre JV, Bailly V, et al. Kidney injury molecule-1 (KIM-1), a putative epithelial cell adhesion molecule containing a novel immunoglobulin domain, is up-regulated in renal cells after injury. J Biol Chem. 1998; 273:4135-4142. [PubMed: 9461608]

30. Smeets B, Boor P, Dijkman H, et al. Proximal tubular cells contain a phenotypically distinct, scattered cell population involved in tubular regeneration. J Pathol. 2013; 229:645-659. [PubMed: 23124355] **This study shows that CD24+CD133+ cells in human kidney also express KidneyInjury Molecule-1, among other markers, suggesting an injury phenotype to these putative progenitors. That adult rat kidney does not contain these cells, but kidney injury upregulates expression of cells with these markers, further suggests that these are injured cells rather than true progenitors.

31. Bianco P, Cao X, Frenette PS, et al. The meaning, the sense and the significance: translating the science of mesenchymal stem cells into medicine. Nat Med. 2013; 19:35-42. [PubMed: 23296015]

32. Humphreys BD, Bonventre JV. Mesenchymal stem cells in acute kidney injury. Annu Rev Med. 2008; 59:311-325. [PubMed: 17914926]

33. Bruno S, Grange C, Deregibus MC, et al. Mesenchymal stem cell-derived microvesicles protect against acute tubular injury. J Am Soc Nephrol. 2009; 20:1053-1067. [PubMed: 19389847]

34. Tomasoni S, Longaretti L, Rota C, et al. Transfer of growth factor receptor mRNA via exosomes unravels the regenerative effect of mesenchymal stem cells. Stem Cells Dev. 2013; 22:772-780. [PubMed: 23082760] * Direct demonstration that MSC deliver mRNAs to injured epithelial cells via exosome-mediated mRNA transfer, including that of insulin-like growth factor-1 receptor.

35. Togel F, Hu Z, Weiss K, et al. Administered mesenchymal stem cells protect against ischemic acute renal failure through differentiation-independent mechanisms. Am J Physiol Renal Physiol. 2005; 289:F31-F42. [PubMed: 15713913]

36. Wang Y, He J, Pei X, et al. Systematic review and meta-analysis of mesenchymal stem/stromal cells therapy for impaired renal function in small animal models. Nephrology (Carlton). 2013; 18:201-208. [PubMed: 23217027]

37. Togel FE, Westenfelder C. Kidney protection and regeneration following acute injury: progress through stem cell therapy. Am J Kidney Dis. 2012; 60:1012-1022. [PubMed: 23036928]

38. Lee RH, Pulin AA, Seo MJ, et al. Intravenous hMSCs improve myocardial infarction in mice because cells embolized in lung are activated to secrete the anti-inflammatory protein TSG- 6 . Cell Stem Cell. 2009; 5:54-63. [PubMed: 19570514]

39. Bi B, Schmitt R, Israilova M, et al. Stromal Cells Protect against Acute Tubular Injury via an Endocrine Effect. J Am Soc Nephrol. 2007; 18:2486-2496. [PubMed: 17656474]

40. Takahashi K, Yamanaka S. Induction of pluripotent stem cells from mouse embryonic and adult fibroblast cultures by defined factors. Cell. 2006; 126:663-676. [PubMed: 16904174]

41. Robinton DA, Daley GQ. The promise of induced pluripotent stem cells in research and therapy. Nature. 2012; 481:295-305. [PubMed: 22258608]

42. Cai J, Zhao Y, Liu Y, et al. Directed differentiation of human embryonic stem cells into functional hepatic cells. Hepatology. 2007; 45:1229-1239. [PubMed: 17464996]

43. Wichterle H, Lieberam I, Porter JA, et al. Directed differentiation of embryonic stem cells into motor neurons. Cell. 2002; 110:385-397. [PubMed: 12176325]

44. Laflamme MA, Chen KY, Naumova AV, et al. Cardiomyocytes derived from human embryonic stem cells in pro-survival factors enhance function of infarcted rat hearts. Nat Biotechnol. 2007; 25:1015-1024. [PubMed: 17721512]

45. Yang YM, Gupta SK, Kim KJ, et al. A Small Molecule Screen in Stem-Cell- Derived Motor Neurons Identifies a Kinase Inhibitor as a Candidate Therapeutic for ALS. Cell Stem Cell. 2013; 
12:713-726. [PubMed: 23602540] **The first study to show that drugs can be validated in vitro using iPS-derived cell types - and that the results may predict results in clinical trials - leading to the concept of "in vitro clinical trials."

46. Kim YJ, Lee G. Candidate ALS Therapeutics Motor toward "In Vitro Clinical Trials". Cell Stem Cell. 2013; 12:633-634. [PubMed: 23746968]

47. Kim D, Dressler GR. Nephrogenic factors promote differentiation of mouse embryonic stem cells into renal epithelia. J Am Soc Nephrol. 2005; 16:3527-3534. [PubMed: 16267156]

48. Bruce SJ, Rea RW, Steptoe AL, et al. In vitro differentiation of murine embryonic stem cells toward a renal lineage. Differentiation. 2007; 75:337-349. [PubMed: 17286599]

49. Vigneau C, Polgar K, Striker G, et al. Mouse Embryonic Stem Cell-Derived Embryoid Bodies Generate Progenitors That Integrate Long Term into Renal Proximal Tubules In Vivo. J Am Soc Nephrol. 2007

50. Batchelder CA, Lee CC, Matsell DG, et al. Renal ontogeny in the rhesus monkey (Macaca mulatta) and directed differentiation of human embryonic stem cells towards kidney precursors. Differentiation. 2009; 78:45-56. [PubMed: 19500897]

51. Song B, Smink AM, Jones CV, et al. The directed differentiation of human iPS cells into kidney podocytes. PLoS ONE. 2012; 7:e46453. [PubMed: 23029522]

52. Davies JA, Unbekandt M, Ineson J, et al. Dissociation of embryonic kidney followed by reaggregation as a method for chimeric analysis. Methods Mol Biol. 2012; 886:135-146. [PubMed: 22639257] * This reviews a protocol for the most rigorous test of kidney progenitor function their ability to incorporate into kidney structures after re-aggregation with embryonic kidney progenitors in vitro.

53. Mae S, Shono A, Shiota F, et al. Monitoring and robust induction of nephrogenic intermediate mesoderm from human pluripotent stem cells. Nature communications. 2013; 4:1367. ** The first comprehensive protocol for the directed differentiation of ES cells toward kidney fates. A strength of the study is the high efficiency with which the authors were able to induce intermediate mesoderm.

54. Zhou Q, Brown J, Kanarek A, et al. In vivo reprogramming of adult pancreatic exocrine cells to beta-cells. Nature. 2008; 455:627-632. [PubMed: 18754011]

55. Hendry CE, Vanslambrouck JM, Ineson J, et al. Direct Transcriptional Reprogramming of Adult Cells to Embryonic Nephron Progenitors. J Am Soc Nephrol. 2013 * This is the first study to demonstrate direct reprogramming of one somatic cell type to a kidney fate. In this case, tubular epithelial cells were reprogrammed to nephron progenitors.

56. Hammerman MR. Tissue engineering the kidney. Kidney Int. 2003; 63:1195-1204. [PubMed: 12631335]

57. Humes HD, Buffington D, Westover AJ, et al. The bioartificial kidney: current status and future promise. Pediatr Nephrol. 2013

58. Humes HD, Weitzel WF, Bartlett RH, et al. Initial clinical results of the bioartificial kidney containing human cells in ICU patients with acute renal failure. Kidney Int. 2004; 66:1578-1588. [PubMed: 15458454]

59. Tumlin J, Wali R, Williams W, et al. Efficacy and safety of renal tubule cell therapy for acute renal failure. J Am Soc Nephrol. 2008; 19:1034-1040. [PubMed: 18272842]

60. Song JJ, Guyette JP, Gilpin SE, et al. Regeneration and experimental orthotopic transplantation of a bioengineered kidney. Nat Med. 2013; 19:646-651. [PubMed: 23584091] ** A remarkable description of a bioengineered kidney generating by decellularizing a rat kidney followed by seeding it with kidney progenitors. The regenerated kidney appears to have some filtration function after transplantation in vivo - providing a crucial proof of principle. 


\section{Key Bullet Points}

1. Whether or not adult kidney harbors a proximal tubule stem cell population remains an unresolved controversy.

2. The use of MSC to prevent AKI is already in Phase II clinical trials, but important gaps in our understanding of how these unique cells exert their renoprotective effects exist.

3. Research into the use of ES and iPS cells as inexhaustible sources of differentiated cell types has grown rapidly in the last year, and promises to be one of the most active areas in kidney stem cell research in the near future.

4. Substantial progress has been made in efforts to generate bioengineered kidneys, either from a decellularized scaffold, or using nano-biotenchnology approaches. 

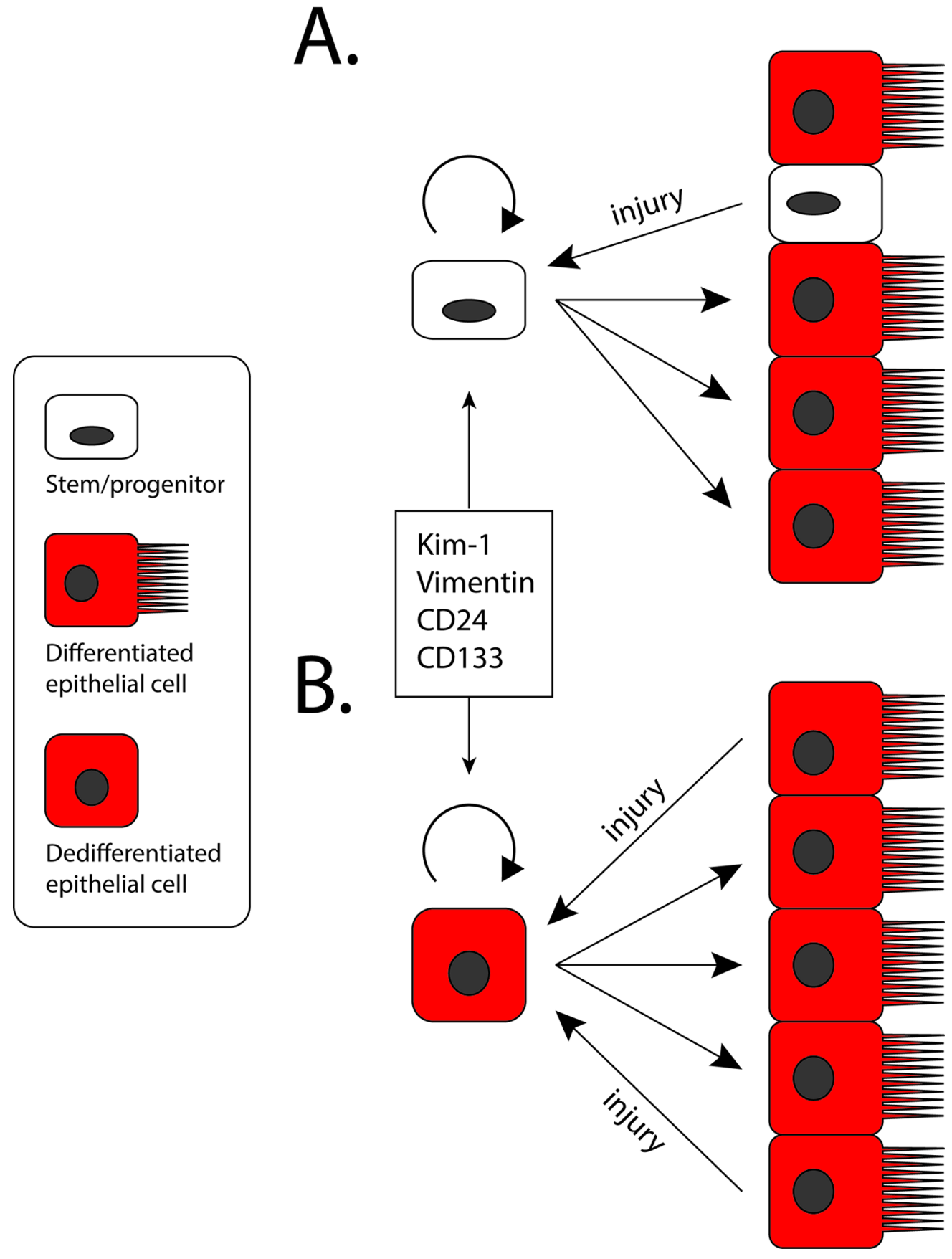

Figure 1. Dueling Models for Epithelial Repair after Injury

(a) In the stem/progenitor model, scattered progenitors located adjacent to differentiated proximal tubule epithelium. After injury, these cells preferentially survive and selectively proliferate. Their progeny differentiate into proximal tubule epithelial cells. The progenitors express CD24, CD133, Kim-1 and Vimentin, among other markers. (b) In the selfduplication model, any fully differentiated cell that survives the injury has an equivalent capacity to dedifferentiate and proliferate. The progeny the re-differentiate into proximal tubule epithelium. In this case, CD24, CD133, Kim-1 and Vimentin are not markers of a separate stem cell compartment, but are injury markers expressed by a dedifferentiated 
epithelial cell. Thus new epithelia derive from their fully differentiated neighbors in a process of self-duplication. 


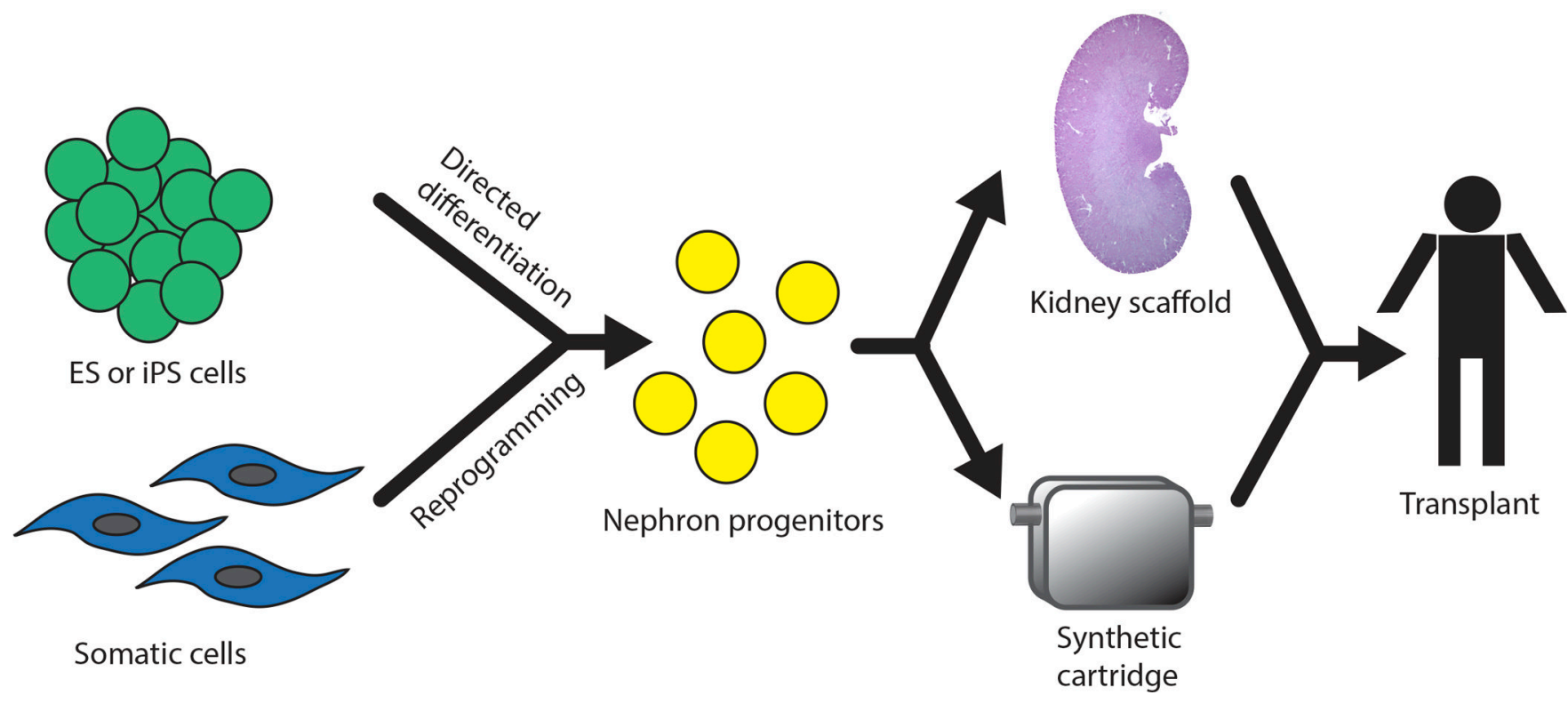

Figure 2. Models to Combine Stem Cells and Kidney Engineering

(a) ES or iPS cells are differentiated into kidney progenitors. Alternatively, somatic cells may be directly reprogrammed into progenitors. These cells are then combined either with a decellularized kidney scaffold, or alternatively with a synthetic cartridge, to differentiate into functional kidney cell types. The goal with both types of engineered kidney is to transplant into humans with kidney failure. 